\title{
Vito Messina. «A New Proposal for Identifying the Kings Represented on the Hung-e Azhdar Rock Relief »
}

\section{Barbara Kaim}

\section{(2) OpenEdition Journals}

Édition électronique

URL : http://journals.openedition.org/abstractairanica/42648

DOI : 10.4000/abstractairanica.42648

ISBN : 1961-960X

ISSN : 1961-960X

Éditeur :

CNRS (UMR 7528 Mondes iraniens et indiens), Éditions de l'IFRI

\section{Référence électronique}

Barbara Kaim, «Vito Messina. «A New Proposal for Identifying the Kings Represented on the Hung-e Azhdar Rock Relief » », Abstracta Iranica [En ligne], Volume 37-38-39 | 2018, document 20, mis en ligne le 10 mars 2018, consulté le 28 septembre 2020. URL : http://journals.openedition.org/

abstractairanica/42648 ; DOI : https://doi.org/10.4000/abstractairanica.42648

Ce document a été généré automatiquement le 28 septembre 2020

Tous droits réservés 


\title{
Vito Messina. «A New Proposal for Identifying the Kings Represented on the Hung-e Azhdar Rock Relief »
}

\author{
Barbara Kaim
}

\section{RÉFÉRENCE}

Vito Messina. «A New Proposal for Identifying the Kings Represented on the Hung-e Azhdar Rock Relief » IA 49, 2014, p. 331-345.

1 L'A. propose une nouvelle interprétation du relief rupestre de Hung-e Azhdar (ou Hung-e Nauruzi). Les recherchés menées récemment par l'expédition conjointe iranoitalienne au Khuzistan (numérisation 3D Haute précision du relief et des fouilles effectuées près de celui-ci) ont fourni des preuves irréfutables qu'il ne s'agit pas d'une représentation de l'hommage rendu par le vassal local d'Elymaïde accompagné de trois dignitaires au roi parthe Mithridate I. Selon l'interprétation convaincante de l'A., le relief a été construit en deux étapes : (1) à la scène réalisée près d'un ancien sanctuaire local qui représente l'un des derniers souverains de la dynastie des Kamnaskirides sur le cheval, (2) puis, au début du 2ème siècle, un autre souverain, probablement Kamnaskires-Orodes, a ajouté les personnages debout et les oiseaux. 


\section{AUTEURS}

BARBARA KAIM

Université de Varsovie 